\title{
Price Regulation in Telecommunications Sector and Its Implications
}

\author{
MUHAMMAD SALEEM
}

\section{INTRODUCTION}

Telecommunication facility has been provided in most countries as a user pay public service managed, typically, through the Post, Telegraph and Telephone departments or by some government-owned monopoly. The tradition has been to regard it as a natural monopoly to be supplied by the public sector. ${ }^{1}$ This perception has changed. Telecommunication is now increasingly recognised as a prime mover of the modern day economy. It is opening to participation by the private sector. The economic benefits of telecommunications are enormous, both as a growth industry in its own right and in terms of its impact on economic development. It has a significant social role in transforming how people communicate, become informed or do business. Additionally, it is also environment-friendly because it disseminates information without shifting goods or people.

The practice now in vogue is to establish a regulatory agency with a high degree of independence from both operator and government. The regulator's task is to implement government policy, ensure performance accountability by the operators and other players in respect of economic and social policy objectives, resolve disputes between competitors, monitor changing industry conditions and advise government on developments bearing on policy. The regulatory agency acts as a buffer between telecom operators and government, helping to ensure the separation of functions.

Of late governments have increasingly been pursuing the policy of privatisation, liberalisation and de-regulation of telecommunication services. Pakistan has also made an advance in this direction with the promulgation of the Pakistan Telecommunications (Reorganisation) Act 1996. The main objectives are the promotion of rapid development, modernisation and diversification of telecommunication services and protection of consumer interest.

In this paper an attempt has been made to answer the question as to why there is need to regulate telecommunication. Determining reasonable prices for a monopoly public service is an important area in telecom sector.

The paper is divided into three sections. We begin by examining why telecom sector requires regulation. Section II provides standards for judging reasonableness

Muhammad Saleem is Director (Economics), Pakistan Telecommunication Authority, Islamabad.

${ }^{1}$ Dnes, A. (1995) Post Privatisation Performance-Regulating Telecommunication in the UK: Testing for Regulatory Capture, The World Bank Note/Viewpoint No. 60. 
of prices in telecommunication industry. Price regulations, different methods of price determination and their implications are analysed in Section III.

\section{WHY REGULATE TELECOMMUNICATION INDUSTRY}

Governments regulate industries in a variety of ways to achieve certain objectives. Some industries have been selected for special treatment because of their unique importance to society. Telecommunications has always been considered an industry of special interest. Telegraph and telephone facilities have traditionally been viewed as important to security and defence while being regarded as a natural extension of governments' social service traditions.

The basic objectives of regulating telecommunication are both economic and social. From an economic perspective the services should satisfy the full range of consumer demand and be supplied under conditions of optimal efficiency. From a social perspective, the services should be made available to everyone on reasonable terms, whether or not it is profitable to do so. The telecom network should be extended not just to the limits of economic efficiency, but to the limits of social need.

In an ideal, perfectly competitive market economy, firms and households are the price takers and the price is determined in the open market. In such a perfectly competitive market economy, resources are employed efficiently. But the competitive model is not an accurate description of the way a real world market for telecommunication industry works. Throughout the world, telecommunication industry exhibits characteristics of "natural monopoly".

An important example of natural monopoly is the local telephone distribution. The cost of sending wires into every home and gathering the wires in a local telephone exchange is very high and it would not be profitable to have more than one firm providing such local telephone service. There is a natural monopoly therefore.

According to the theory of natural monopoly, an industry is a natural monopoly if the entire market demand can be served at a lower cost by a single firm than by two or more firms and natural monopolists enjoy enormous monopoly profits and in face of price inelastic demand, can jack up prices sharply, and create major economic inefficiencies. ${ }^{2}$ To see this consider Figure 1.

An unregulated monopolist sells $\mathrm{Q}_{\mathrm{m}}$ output at a price of $\mathrm{P}_{\mathrm{m}}$ in order to maximise profit. The output is less than what the society desires and the price is also higher. Efficient allocation of resources occurs at $\mathrm{F}$, where marginal cost intersects the demand curve (the marginal cost of producing $Q_{c}$ output corresponds to the price consumers are willing to pay). However, if the regulatory commission sets the price at $P_{c}$, the firm will not produce in the long-run as the price is less than the long-run average costs. To ensure long-run production by limiting the firm to normal profit, the regulatory commission may choose to equate price with a long-run average cost E. Confronted with a price of $\operatorname{Pr}$, the firm will produce $Q_{r}$ output.

${ }^{2}$ Smith, Peter (1995) Subscribing to Monopoly: The Telecom Monopolist's Lexicon—Revisited, The World Bank Note/Viewpoint No. 53. 


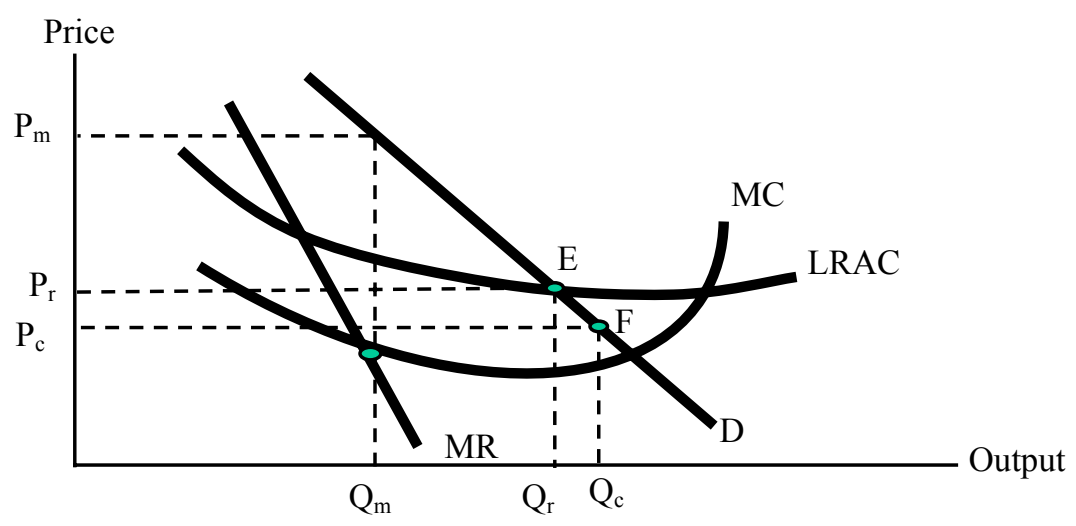

Fig. 1.

Given that natural monopolies will earn enormous profit if unchecked by the government, or they will not produce if they are forced to charge marginal cost pricing, what options are available to the government to provide services to its consumers?

(i) One alternative is to subsidise natural monopolies. This entails imposition of taxes to fund the subsidy. Such taxes would almost certainly have nonneutral distribution impact.

(ii) The other alternative is public ownership of telecommunication industry which has been prevalent in Pakistan.

As operator and owner of the telecommunication sector, the Pakistan government has been drawn into day-to-day interventions in its operations. The Pakistan Telecommunication Company Ltd., being the monopoly provider of basic telephony service in Pakistan with exclusivity until end of 2002, it was felt that some form of regulatory body be set up, as part of a broader governmental effort, to redefine the respective roles of the government, telecommunication industry and consumers. This implied a shift away from the monolithic type of governmental management towards a decentralised and market-based system with the government retaining responsibility for setting objectives, making overall policies and planning and coordinating development. Towards this end the Pakistan Telecommunication Authority (PTA) was established under the Pakistan Telecommunication (Reorganisation) Act of 1996. It would regulate telecommunication licensing, decide tariffs, approve equipment type, make interconnection arrangements etc. ${ }^{3}$

The challenge here is not specifying the policy and regulatory objectives in the new environment, but implementing them effectively. These objectives are not static objectives to be achieved once, but must be maintained in a very dynamic

${ }^{3}$ Pakistan Telecommunication Authority (1997) Annual Report, Islamabad. 
environment. The structure of government/industry relations may be the most important factor influencing future success, and that will depend significantly on the effectiveness of the model of regulation that is adopted. But regulatory approaches need to establish an appropriate balance between protection of public interest and the need for enterprise autonomy.

\section{STANDARDS FOR JUDGING REASONABLENESS OF PRICES}

Both historically and currently, the topic that has attracted the greatest attention in the field of regulated industries has been the reasonableness of prices. As a monopoly, or a dominant firm with significant market ownership, the regulated firm has a market incentive to charge monopolistic prices for a public necessity service. One important task of regulation has been to ensure that the prices charged to consumers are reasonable. This has led to a search for standards by which the reasonableness of prices can be judged.

Regulators have attempted to judge the reasonableness of prices in telecom industries by evaluating "reasonableness" from four different perspectives or levels of analysis: ${ }^{4}$

(i) Specific individual prices, e.g. the line charges for a telephone;

(ii) Relations between specific prices, e.g., a telephone line compared to an ISDN line. This raises issues of appropriate rate relations, the design of the rate structure and price discrimination;

(iii) The revenue level of a specific class of service involving several specific services, prices and rate structures, e.g. local telephone services; and

(iv) The overall revenue level of the company for all of its regulated services.

Recognising the inherent imperfections of all real world assessments, reasonableness is sometimes viewed as encompassing a range of possible prices, with maximum prices for monopoly services being judged as the top of the range of reasonableness. As competition becomes more significant, claims are sometimes made that the monopoly operators are charging prices for special services subject to competition that are too low. In this circumstance regulation and competition authorities are sometimes required to make judgments about minimum reasonable prices. Reasonableness of prices is based on the following.

\section{(i) Equity}

If basic telecom services are considered to be a public necessity everyone should have reasonable access to, then a standard of reasonableness must satisfy that

${ }^{4}$ Melody, W. H. (1997) "Interconnection: Cornerstones of Competition" in Telecom Reform; Principles, Policies, and Regulatory Practices, edited by the same author, Technocal University of Denmark, Lyngby. 
primary objective. To cover the poor and the disabled the standard of reasonableness used is based on equity considerations such as "need" and "ability to pay" to determine the maximum price for a limited number of specific services such as network access and minimum levels of usage. This normally covers a few of the total number of services and prices offered by any operator.

\section{(ii) Efficiency}

The economic standard of cost is derived from the theory of efficient resource allocation, in particular the standard of optimal efficiency in theoretical terms in perfectly competitive markets. Clearly if prices are set below cost, there will be no incentive to supply those services in private markets. Either people would be denied services they were willing to pay for, or there would have to be a transfer of economic resources from other important areas so as to subsidise their supply.

Cost is not an easy standard to define or implement. The cost of production of one firm may be a lot higher than another's for producing the same service. Clearly society is better off if the service is supplied by a firm that can do it best. Competitive markets provide a powerful incentive for firms to be efficient and to seek ways of improving their efficiency. If a firm is the most efficient competitor, it may earn extra profit for a while until its competitors catch up with it.

\section{(iii) Improving Performance}

The primary objective is to get these national operators to improve their performance dramatically in a sustained manner over an extended period. The effort is not only to reduce costs to an efficient level, but also to stimulate investment in network upgrading, improved customer service and new service development. Competition is seen as a stimulus, but competition can hardly be expected to cover the entire market, or to provide residential basic subscribers with competitive market options for a long time. The objective is to drastically reduce the operator monopoly power while at the same time turning it into an efficient and effective competitor.

\section{PRICING METHODOLOGIES AND ITS IMPLICATIONS}

Regulators can determine prices and profits constraints on the regulated firms in a variety of ways. Prices are based either on costs or on demand. Often the cost concepts are considered for cost-based pricing including rate of return and markup. Some notable methods are:

- Marginal Cost Pricing.

- Average Cost Pricing.

- Ramsey Pricing Rule.

- Rate of Return Regulation.

- Price Caps. 


\section{(i) Marginal Cost Pricing}

In theory, marginal costs are the costs that are associated with an increase or decrease of one unit of output, such as an additional call minute or a new access line. Mathematically, both long-run marginal cost and short-run marginal cost can be expressed in the same way. The marginal cost (MC) (whether long-run or short-run) is the first derivative of the total cost function. Denoting total cost by $\mathrm{C}$ and output by $\mathrm{X}$, we have:

$$
M C=\partial \mathrm{C} / \partial X
$$

In a competitive market, firms set prices equal to marginal costs, as this implies that output prices reflect the underlying supply costs of producing that output. For the national economy as a whole, marginal cost pricing means that scarce resources are being used in the most productive way possible, as no alternative use of these resources would yield higher benefits, resulting in the maximum possible contribution to the national economy.

Although marginal cost pricing appears to offer benefits to all stakeholders, there are a number of practical problems associated with the use of marginal cost pricing for the PTCL. Telecommunication companies, such as PTCL does not have an adequate cost data to calculate marginal costs reasonably. Like any other telecommunication firm, PTCL makes investment for capacity in blocks and not in units (investment is lumpy) and elements of its cost structure are common in a number of outputs. For instance, local exchange switching equipment is used by local, long distance and international calls, and is typically bought in block capacity.

\section{(ii) Average Cost Pricing}

The basic characteristic of average cost pricing is the postulate that price is set according to the average cost principal. Symbolically:

$$
P=A V C+G P M=A C
$$

Where $P=$ price, $A V C=$ average variable cost, $G P M=$ gross profit margin, $A C=$ average cost.

Given that most of the telecommunication firms are decreasing cost firms and their costs are largely fixed according to service consumed, it implies that setting prices equal to marginal costs will incur chronic losses. In view of these losses, regulators have traditionally relied on average cost pricing for the regulated firms. For example, a telephone company would take all its cost (fixed as well as variable) and distribute them to each product sold (say local calls and long distance calls). Then each class of customers would be charged the fully distributed average cost of that type of service. 
Besides the problems of measuring and unbundling costs, the average cost pricing method has been criticised on the following grounds:

(a) Unlike the marginal cost pricing, average cost pricing is not considered the first-best pricing method.

(b) Since price is based on the costs of the firms, the average cost pricing method may lead to discarding demand for telecommunications subscribers.

(c) Under the average cost pricing method, the prices charged to consumers will be higher than the prices charged under marginal cost pricing method. This is because average cost pricing is based on budgeted output which implies use of exchanges (on the average) is below 100 percent capacity. This further implies under utilisation of exchanges.

\section{(iii) Ramsey Pricing Rule}

A widely acknowledged rule for determining a markup to minimise deviation form efficiency is the Ramsey Rule. This rule states that the markup of price over marginal cost should be in inverse proportion to the elasticity of demand for the products. It states that to meet a given revenue requirement, while minimising the loss of net benefit from consumption, the deviation of price from marginal cost should vary inversely proportional to the own price elasticity of demand.

This can be stated as follows:

$$
(P-M C) / P=(\lambda-1) / e
$$

Where $P=$ price, $M C=$ marginal cost, $e=$ price elasticity of demand, $\lambda=$ Constant associated with profit constraint.

The Ramsey pricing approach requires extensive data on consumer demand for services and particularly the responsiveness of demand to price changes. While PTCL does not have an adequate data on the responsiveness of demand to price changes, a pragmatic solution would be to use whatever data is available to understand the implications of this approach that might show the general direction in which tariffs could be adjusted. For instance, our analysis shows that trunk calls in Pakistan have a relatively high elasticity and monthly rentals have low elasticity. Ramsey pricing would suggest a proportionately lower mark up on trunk calls relative to monthly rentals.

Regulators around the globe have been slow to approve the Ramsey pricing technique due to the following reasons:

- Ramsey pricing rule could lead to unfair price discrimination.

- Lack of sophistication in billing systems.

- Lack of adequate data on the responsiveness of demand to price changes.

\section{(iv) Rate of Return Regulation}

Under the rate-of-return regulation, telecommunication prices are set to reflect the embedded or historical costs of providing services to each set of customers. Rate 
increases are based on a telecommunication utility's revenue requirements - this is, to provide a reasonable return on equity. The revenue requirement can be expressed as:

$$
R R=E+d+T+(V-D) R
$$

Where:

$$
\begin{aligned}
R R= & \text { revenue Requirement; } \\
E= & \text { operating Expenses; } \\
d .= & \text { annual Depreciation Expenses; } \\
T= & \text { taxes, including Income Tax; } \\
V= & \text { gross Valuation of the Property Serving the Public; } \\
D= & \text { accrued Depreciation; } \\
R= & \text { percentage Rate of Return; } \\
V-D= & \text { net Value of Rate Base (includes the physical assets such as land } \\
& \text { buildings, and transmission facilities in use); and }
\end{aligned}
$$

$(V-D) R=$ rate of Return Permitted on Rate Base.

The rate-of-return regulation has been used extensively in the United States, where until recently it has been applied to investor-owned public utilities, including telecommunications. Typically, it has involved the establishment of a maximum permissible percentage ceiling on a company's rate of return on equity, after taxation and interest charges. The companies are then obliged to set their prices for various services at levels which result in overall earnings which are at or below the permissible rate of return. The rate of return ceiling may be applied at various levels of aggregation, from an individual service to the full range of a company's regulated activities.

The main disadvantage of the rate-of-return regulation is that it provides no incentive to control costs: higher costs can simply be passed on to the consumer in the form of higher prices. Rate-of-return controls can provide an incentive for management to "gold-plate" its investment process which can lead to an undue regulatory influence on management's commercial decisions.

\section{(v) Price Caps}

Price cap is a very flexible pricing methodology, and can be adjusted to take account of a variety of objectives related to telecom tariffs. ${ }^{5}$ An important reason for adopting price caps has been to facilitate the process of tariff restructuring, i.e. change the prevailing pattern of cross-subsidisation among services. Most OECD countries use some form of price cap for regulating telecom tariffs.

The basic idea in the price cap methodology is to consider two elements. One is an estimate of inflation of the costs of producing a specified basket of telecom services. The other is the likely increase in the operator's productivity for that basket of services. The former is approximated by the rate of inflation in the economy (or $\mathrm{CPI}$ ) and the latter is characterised by a factor $X$. The price cap formula normally

${ }^{5}$ Rohlfs, J. H. (1996) Regulating Telecommunication; Lessons from U.S. Price Cap Experience, The World Bank Note/Viewpoint No. 65. 
specifies that for a particular basket of telecom services, the average price cannot increase beyond a factor CPI minus $X ;(C P I-X)$. For example, if the maximum annual price increase was "CPI-5" and the CPI rose by 17 percent over the year, prices would be allowed to rise by 12 percent. Prices charged by the operator for the Basket Services shall be set so as to satisfy the criteria in the following:

$$
1+\sum_{\mathrm{I}}\left(W_{i} / W\right) \times\left[\left(P_{i}^{t}-P_{i}^{t-1}\right) / P_{i}^{t-1}\right] \leq\left[C P I^{t-1} / C P I^{t-2}\right]-X^{t} / 100
$$

Where:

$C P I=$ the consumer price index;

$C P I^{t-1}=$ the consumer price index $t-1$ period;

$P i^{t-1}=$ the geometric average price of basket service $i$ in the period ( $\left.\mathrm{t}-1\right)$;

$P i^{t}=$ the geometric average price of basket service $i$ for the current price $(\mathrm{t})$;

$W_{i}=$ the revenues of basket service $\boldsymbol{i}$ in the latest financial year;

$W=$ the total revenues of all basket services in the latest financial year; and

$X^{t}=$ the ' $\mathrm{X}$ ' factor is designed to encourage cost saving and efficiency improvements.

In the telecommunications sector, price caps have been applied to dominant carriers in the UK, Australia and the US (AT\&T and the Regional Bell operating companies), as well as an increasing number of developing countries such as Argentina. In our view, the price cap method would also be the most appropriate approach to adopt in Pakistan. This is primarily because:

- it eliminates the need to obtain political approval for individual price increases and, by taking price policy out of the political control, it provides an element of certainty for management and investors that should facilitate rational planning and help to create a climate which encourages private sector participation in the sector; and

- it provides an incentive to improve efficiency, as cost reductions will be reflected directly in higher profits.

The main disadvantage of the price cap approach is that unexpected changes in costs can give rise to profits which are unacceptably high or inadequately low. Price caps are therefore inappropriate in industries which are prone to unexpected fluctuations in the level of costs. Fortunately, the telecommunications industry is not generally prone to such fluctuations, although the costs of imported equipment can be affected by a volatile exchange rate.

\section{CONCLUSION}

Telecom prices are a crucial component of any policy initiative to foster growth, enhance efficiency and impart dynamism to the sector. Prices affect economic decisions of investors, producers, buyers and sellers in any market, and 
reflect important information about the prevailing and expected market situation. Moreover, if there is a competitive pressure on prices, producers are likely to be more alert about improving their performance and taking account of dynamic developments. All these aspects provide a basis for linking prices with the achievement of various socio-economic objectives.

The different standards for judging the reasonableness of prices discussed in this paper - equity, efficiency (rate of return) and improvement performance (CPI-X) - are not substitutes for one another. They provide standards for judgement from different perspectives. Ideally, reasonable rates should satisfy all standards. However, they sometimes conflict. The priorities placed upon application of the different standards depend very much on the particular circumstances in which they are being applied, and these priorities can be expected to change with obtaining circumstances.

The challenge for the future will be to build on experience and fashion the most appropriate standards for judging the reasonableness of telecom prices after the PTO transformation, in highly imperfect, partially competitive markets. Neither the rate of return nor the CPI-X methods have been demonstrated to be effective in preventing cross-subsidy, i.e., in providing a consistent basis for simultaneous judgements about reasonable maximum prices for monopoly services and reasonable minimum prices for competitive services. Neither method will be very helpful in resolving the future debate about whether information services should be priced primarily as access charges or usage charges. Moreover, some evidence points to the possibility that many dominat PTOs may not rank the potential to earn extra profit nearly as high as preserving their market share and establishing outposts of competition to restrict entry by new competitors. In the new environment regulators

will have to take more intensive and detailed examinations of PTO cost structures as a foundation for their rate structures.

\section{REFERENCES}

Dnes, A. (1995) Post Privatisation Performance-Regulating Telecommunication in the UK; Testing for Regulatory Capture. (The World Bank Note/Viewpoint No. 60.)

Melody, W. H. (1997) Interconnection: Cornerstons of Competition. In W. H. Melody (ed.) Telecom Reform; Principles, Policies, and Regulatory Practices. Lyngby: Technocal University of Denmark.

Pakistan Telecommunication Authority (1997) Annual Report. Islamabad.

Rohlfs, J. H. (1996) Regulating Telecommunication; Lessons from U.S. Price Cap Experience. (The World Bank Note/Viewpoint No. 65.)

Smith, Peter (1995) Subscribing to Monopoly; The Telecom Monopolist's Lexicon-Revisited. (The World Bank Note/Viewpoint No. 53.) 


\section{Comments}

The central theme of the paper by Muhammad Saleem is related to the question as to why do we need to regulate telecommunication and, particularly, what should be considered as reasonable price for any telecommunication service. Apart from furnishing the theoretical economic basis for determination of this level, he has attempted to justify the need for an effective agency independent of Government interference in its day to day business to regulate the telecommunication industry by establishing an appropriate balance between the two conflicting objectives i.e. protection of consumers' interests and the need for enterprise economy. Obviously this is a very challenging job and needs to be carried out with utmost professional competence and dynamism. It was in this context that the Government of Pakistan established the Pakistan Telecommunication Authority (PTA) in accordance with the Pakistan Telecommunication (Re-organisation) Act, 1996 to regulate telecommunication industry to promote the availability of a wide range of high quality, efficient, cost effective and competitive telecommunication services throughout Pakistan. The Authority has recruited the necessary professional staff. Procedures and regulations have been framed to ensure a transparent regulatory regime. The Authority is thus fully functional to discharge the regulatory responsibilities.

The subject matter of this paper is of great interest to all of us because telecommunication has been recognised as an integral part of both economic and social development throughout the world. This is the largest global industry representing nearly 20 percent of world trade. This sector has seen unprecedented growth in recent years and future growth rates are expected to be much higher. The telecom system is rapidly becoming the electronic infrastructure for transmission of all kinds of information-voice, data, graphics, video, and music. The telecom networks and services provide the foundation for national "information society" programmes as well as a fast growing information economy.

At present, there is much discussion going on about the most effective role telecommunication regulators can play in resolving the complex regulatory issues facing this sector and more importantly within the framework of emerging market structures and regulatory reforms in the public utilities. The requirements of WTO regime make the position further challenging. In the circumstances, it will not be advisable to adopt any specific regulatory model to national structures unless its suitability has thoroughly been examined. PTA as a telecom regulator is, therefore, carefully reviewing the whole position. For this purpose it has arranged open forum discussions and public debates on important regulatory issues including tariffs. 
On the pricing regulation, different models are available which have been applied in different countries. However, controversy still exists as to what is the reasonable price of a telecom service. Economic theory on the issue has been clear for a long time that reasonableness is judged with reference to costs. Prices should be set to cover all economic costs in order to attract the necessary resources. Prices in excess of economic costs simply result in monopoly profits. This economic theory has however failed at the implementation stage particularly when it can create powerful incentives for in-efficient and anti-competitive behaviour. The application of Price Cap regulation has also shown some major theoretical and measurement weaknesses in the United Kingdom although this method has enabled some informed regulators to negotiate a share of benefits in favour of consumers accruing from the efficiency gains through major restructuring of national Public Telecom Operators (PTOs). In the final analysis, therefore, national telecom regulators will have to resolve the issues themselves in the light of local conditions and international experience. PTA has already established a strong base for public consultation on such regulatory issues. The Advisory Committees have been appointed at the Headquarters level as well at the Regional Offices. A study was recently carried out in collaboration with the World Bank on demand and tariff for telecommunication services in Pakistan. This is the first Study of its kind for Pakistan. Furthermore, research is being carried out within PTA on salient features of this Study. A number of open public hearings were held in PTA on regulatory awareness and tariff issues. Opinion on different regulatory matters is also being solicited through the PTA web site. PTA finalised its draft policy on Universal Service Obligations through this process of consultation. We are hopeful that the Pakistan Society of Development Economists and PIDE will continue to provide their professional guidance to PTA to facilitate the solution of intricate regulatory issues and thus promote economic regulation in Pakistan.

Pakistan Telecommunication Authority,

Abdul Khaliq Awan Islamabad. 